International Journal of Child, Youth and Family Studies (2011) 1 \& 2: 12-35.

\title{
THE IMPORTANCE OF NEUROPSYCHOLOGICAL DEFICITS RELATING TO SELF-CONTROL AND TEMPERAMENT TO THE PREVENTION OF SERIOUS ANTISOCIAL BEHAVIOR
}

\section{Matt DeLisi and Michael G. Vaughn}

\begin{abstract}
The current article is a targeted review of two biosocial constructs, neuropsychological deficits relating to self-control and temperament, which as demonstrated by prior researchers are importantly related to antisocial behavior, importantly related to other constructs that influence antisocial behavior, such as aggression, and importantly related to prevention efforts. We explicate what is known about neuropsychological deficits relating to self-control and temperament specifically vis-à-vis prevention and early intervention programs that seek to preclude the development of costly antisocial careers.
\end{abstract}

Keywords: temperament, self-control, prevention, neuropsychological deficits, conduct problems

The basic logic of prevention studies is to target populations that present with an assortment of risk factors for antisocial behavior and provide educational, medical, and psychological services and other treatment modalities that will theoretically mute the likelihood that the risk factors will manifest in problem behavior. From an array of disciplinary and even ideological perspectives, prevention is hailed as a humanistic, costeffective, and demonstrably effective way to prevent antisocial conduct and related social problems (DeLisi, 2005; Earls, 1998; Elliott, 1998a, 1998b; Farrington \& Coid, 2003; Farrington \& Welsh, 2007; Litschge, Vaughn, \& McCrae, 2010). Moreover, prevention programs figure prominently in criminal justice policies that span across the various components of the justice system including law enforcement and corrections (e.g., Braga, 2008; Foley, 2008; Mears, 2007; Mears \& Bacon, 2009; Mears \& Barnes, 2010; Worrall et al., 2009).

A major reason for the appeal of prevention stems from its cost-effectiveness at forestalling the development of costly criminal careers. In a seminal study on the value of crime prevention, Cohen (1998) calculated that the average costs imposed by a serious delinquent offender ranged from $\$ 1.5$ to $\$ 1.8$ million in terms of victimization costs, criminal justice system expenditures, productivity losses, and quality of life reductions.

Matt DeLisi, Ph.D. is Assistant Professor in the Department of Sociology and Coordinator of the Criminal Justice Studies Program at Iowa State University.

Michael G. Vaughn, Ph.D. is Assistant Professor in the School of Social Work at Saint Louis University. 
International Journal of Child, Youth and Family Studies (2011) 1 \& 2: 12-35.

Subsequent monetization studies have largely confirmed that an individual serious, violent, and chronic juvenile offender can inflict costs in excess of \$1 million (Cohen, 2005; DeLisi \& Gatling, 2003) with dramatically higher monetization estimates found for adult career criminals and homicide offenders (Cohen \& Piquero, 2009; DeLisi et al., 2010; Welsh et al., 2008). In sum, the social and correctional expenditures and more important human toll created by serious offenders warrant investment in prevention programs not only to save social dollars, but also to preclude the suffering and victimization that accompany crime.

\section{The Promise of Prevention}

Across an array of studies, the evidence for the value of prevention is compelling. Initiated in 1962, the High/Scope Perry Preschool project traced the development of 123 impoverished African-American children who at ages 3 and 4 were randomly assigned into a treatment/program or control group (Schweinhart, Barnes, Weikart, Barnett, \& Epstein, 1993). The treatment group received the High/Scope active learning preschool program consisting of 15 hours of classroom time per week in addition to a 1.5-hour home visit per week. Children in the control group remained at home with their family and received no preschool program. Both groups were assessed for follow-up until age 10 , and again at ages $14,15,19$, and 27 . Through age 27 , the differences in life circumstances across groups are stark. Weikart (1998) found that whereas 7\% of those who received the High/Scope preschool program accumulated five or more arrests, the prevalence for those who did not receive the program was 35\%. There were also significant differences in terms of ever being on welfare (59\% for program and $80 \%$ for controls), graduating from high school on time (66\% for program and $45 \%$ for controls), earning more than \$2,000 per month (29\% for program and $7 \%$ for controls), and home ownership (36\% for program and 13\% for controls). In addition to these benefits, for every dollar invested in the High/Scope Perry Preschool project, \$7.16 in criminal justice and social welfare costs were saved.

In a series of landmark studies, Olds and his colleagues (Olds et al., 1997) found that young, at-risk mothers in rural New York State who received home visits from nurses during their pregnancy and through their child's second birthday experienced significantly better life chances than controls evidenced by reduced welfare dependency, reduced child abuse and neglect, reduced criminal behavior, and fewer subsequent pregnancies. The program also significantly improved the quality of parenting and the overall health of their children through the preschool period (Olds, Henderson, \& Kitzman, 1994). More importantly perhaps, the beneficial effects also extended to the children of mothers who received the nurse home visits. Compared to controls, adolescents born to mothers who received the intervention had fewer arrests, less criminal justice system involvement and reduced criminal justice system noncompliance, reduced incidence of running away, fewer lifetime sexual partners, and reduced alcohol and cigarette use (Olds et al., 1998).

Replications of the study among primarily African-American women in Memphis, Tennessee yielded similarly impressive effects. Women who received nurse home visits 
International Journal of Child, Youth and Family Studies (2011) 1 \& 2: 12-35.

demonstrated greater social competency, less welfare dependency, and greater family stability. Moreover, children of mothers who received nurse home visits demonstrated higher intellectual functioning and lower aggression, and these effects endured through age 6 (Olds et al., 2004). Through age 12 compared to controls, children of mothers who received nurse home visits reported reduced usage of alcohol, cigarettes, and marijuana, fewer internalizing disorders, better reading and math scores, and higher reading and math scores on standardized tests. Curiously, there were not significant differences for externalizing or total behavioral problems (Kitzman et al., 2010).

Over the years, a range of prevention studies have yielded impressive and, at times, long-term benefits toward the reduction of delinquency and related maladaptive behaviors. Although some prevention programs are comprehensive and require considerable financial, labor, and time investments, others are relatively brief and inexpensive. For instance, Walton et al. (2010) conducted a recent randomized controlled trial examining the effects of an emergency department visit to at-risk youth on violent delinquency and alcohol use. A control group of youths received an instructional brochure containing information about the risks of violence and alcohol use. Treatment groups received either a 35-minute computerized instruction or therapist-delivered instruction with follow-up at three and six months. Participants who received the therapist intervention demonstrated the greatest improvements in behavior including reduced peer aggression and violence at three months and reduced alcohol usage at six months. Compared to controls, youths who participated in the computerized intervention also reported reductions in alcohol problems at six months. Today, prevention is a primary example of translational research where theory and practice meet.

\section{The Limits of Prevention}

Despite the widespread respect that prevention is accorded, there are limitations that are important to consider especially when the outcome measure of interest is serious antisocial behavior. To date, the bulk of prevention studies have targeted at-risk mothers and their children with a general aim to improve parenting skills and behaviors that are importantly related to the psychosocial health of the family and to improve the educational, social, and cognitive functioning of the children (Olds, 2002). And it is in these areas where the bulk of prevention's success resides. But when the constructs of interest center on the antisocial propensity of youth, success is more difficult to achieve. As discussed earlier, in the nurse-family replication in Memphis, there were not significant externalizing behavioral differences between treatment and control youths. The null effects of prevention programs on conduct problems are not unique to that program. In a recent review, Tremblay (2006) made pointed observations about this issue:

there is as yet no research on the effects of preschool education programs that would help children at risk of chronic physical aggression to learn alternatives to physical aggression... Some have shown long term impact on antisocial behavior, but most, if not all of these experiments, have not assessed or reported on the 
International Journal of Child, Youth and Family Studies (2011) 1 \& 2: 12-35.

development of physical aggression. Also, to my knowledge, none have shown a reduction of physical violence during adolescence. (p. 486)

An important point of consideration should be taken from Tremblay’s (2006) critique. Tremblay notes that prevention programs have been less successful reducing conduct problems that are associated with individual-level constructs, such as aggression. This is suggestive that biopsychological constructs like aggression are potentially more resistant to interventions than social process constructs like parenting. Concomitantly, this speaks to the relevance of biological and biosocial phenomena to these individuallevel factors that appear resistant to the treatment-oriented mechanisms of the program. ${ }^{1}$

Tremblay is not alone in this regard. It is understood that antisocial conduct is a multifactorial outcome influenced by biological factors, social factors, and their interaction (Caspi et al., 2002; Dodge \& McCourt, 2010; Moffitt, 2005; Moffitt, Caspi, \& Rutter, 2006; Shaw \& Gross, 2008). Moreover, it is believed that biological constructs are central to the unfolding of conduct problems over time. For instance, in a recent metareview of life-course-persistent offending, Eme (2007, p. 621, emphasis added) concluded, "There is strong scientific consensus that life-course persistent CD [conduct disorder] represents the most virulent type of CD, that this type of CD is virtually an exclusive male phenomenon, and that biological variables play a major role in its development." Although life-course-persistent offending per se has not been a target of prior prevention programs, it is precisely the kind of multifaceted problem syndrome that programs do attempt to preclude.

\section{Current Focus}

With this in mind, the current article is a targeted review of two biosocial constructs, neuropsychological deficits relating to self-control and temperament, which as demonstrated by prior researchers are importantly related to antisocial behavior, importantly related to other constructs that influence antisocial behavior, such as aggression, and importantly related to prevention efforts. The current research purpose is to explicate what is known about neuropsychological deficits relating to self-control and temperament, specifically vis-à-vis prevention and early intervention programs that seek to preclude the development of costly antisocial careers.

\footnotetext{
${ }^{1}$ Our approach is not original in that prevention researchers and other scholars are similarly interested in these constructs (see Tremblay, 2010; Tremblay \& Szyf, 2010; Wachs \& Kohnstamm, 2001). For instance, Olds (2002) discussed child neurodevelopmental impairment as consisting of emotional/behavioral dysregulation and cognitive impairment which are analogs of temperament and neuropsychological deficits respectively. But, in Olds' (2002, p. 155) model, these were the outcomes of prenatal health-related behaviors of the mother, birth/perinatal complications, and child abuse and neglect injuries. Although these environmental effects are important, they fail to mention that neuropsychological deficits and temperament are also heritable and thus have a strong biological/genetic basis (Kagan, 1994, 2010).
} 
International Journal of Child, Youth and Family Studies (2011) 1 \& 2: 12-35.

\section{Neuropsychological Deficits Relating to Self-Control}

Neuropsychological functions broadly refer to cognitive and self-regulation processes, such as concentration, motor and cognitive planning, attention, goal formulation, self-awareness and self-monitoring of behavior, and perhaps most importantly, the suppression or modulation of cognitive and behavioral impulses (see Ishikawa \& Raine, 2003). Of particular importance for understanding neuropsychological functioning in antisocial or delinquent individuals are lower-order executive functions including behavioral impulsivity, cognitive impulsivity, and operant decision making. In the developmental psychopathology literature, the emotional, affective, visceral processes demonstrated by antisocial persons are referred to as "hot" components of executive functioning (see Séguin, Arsenault, \& Tremblay, 2007).

In Moffitt’s (1993) seminal developmental taxonomy, neuropsychological deficits are a central causal factor for the social, cognitive, and conduct impairments demonstrated by individuals with lifelong problem behaviors, in her model known as the life-course-persistent prototype. Children who have neuropsychological deficits present with a range of problems relating to verbal skills, receptive language, sustaining attention, memory, response inhibition, and self-control (see also, Barker et al., 2007; Moffitt \& Henry, 1989; Moffitt \& Silva, 1988; Séguin, Nagin, Assaad, \& Tremblay, 2004; H. White, Bates, \& Buyske, 2001; J. White et al., 1994). In school settings, these deficits create a host of problems for the child whose cognitive deficits and the maladaptive behavioral responses to those cognitive problems set into motion a dynamic, negative process whereby the youth becomes estranged from school and conventional peers. This cascade of negative interactions between the neuropsychological deficits and the responses to them also occur at home and in other social settings and contribute to aversive, often punitive responses from adults.

Consistent with theoretical expectations, neuropsychological deficits relating to self-control are strongly related to antisocial dispositions and diverse forms of externalizing behaviors and psychopathological conditions (Barkley, 1997; Beaver, DeLisi, Wright, Vaughn, \& Boutwell, 2008; Hinshaw, 1987, 1992; Hinshaw, Carte, Sami, Treuting, \& Zupan, 2002; Ishikawa \& Raine, 2003; Nigg, Hinshaw, Carte, \& Treuting, 1998). In a comparative study of children with ADHD only, ODD/CD only, comorbid ADHD and ODD/CD, and controls, Clark, Prior, and Kinsella (2000) found that the most severe group - children with both ADHD and ODD/CD - demonstrated the greatest neuropsychological deficits compared to their peers with and without neurobehavioral disorders. Drawing on data from 325 individuals selected from the Pittsburgh Youth Survey, Raine et al. (2005) found that males on the life-coursepersistent pathway had significantly greater neuropsychological deficits compared to behaviorally less severe comparison groups. Specifically, life-course-persistent offenders scored significantly worse on four measures of intelligence, two measures of spatial memory, and one measure of executive functioning. The life-course-persistent group also had a higher prevalence of ADHD diagnosis, higher child abuse victimization, higher child neglect victimization, more extreme family poverty, and had a greater number of head injuries that resulted in unconsciousness. 
International Journal of Child, Youth and Family Studies (2011) 1 \& 2: 12-35.

In a longitudinal designed study with nationally representative data, Beaver, DeLisi, Vaughn, and Wright (2010) found that deficits in verbal skills were predictive of delinquency, violent delinquency, and low self-control across two waves of data that extended through adolescence. In a latent class analysis of data from the Early Childhood Longitudinal Survey-Kindergarten Class, Vaughn, DeLisi, Beaver, and Wright (2009) found that $9.3 \%$ of kindergartners comprise a severe impairment group characterized by deficits in verbal skills and attendant problems with higher impulsivity, higher externalizing behaviors, reduced self-regulation, reduced cognitive abilities, and greater classroom difficulties. In criminological research, a neuropsychological profile including but not limited to impulsivity, externalizing behaviors, and reduced self-regulation are so central to crime and delinquency that a sociologically-informed self-control construct (Gottfredson \& Hirschi, 1990) was recently reformulated into a theory of lower-order executive functioning (Beaver, Wright, \& DeLisi, 2007).

Fortunately, there is evidence that neuropsychological deficits relating to selfcontrol can be targeted for prevention and intervention. For example, the Tools of the Mind curriculum targets inhibitory control, working memory, and cognitive flexibility among at-risk preschool children. The Tools of the Mind curriculum consists of 40 activities that are designed to promote lower-order executive functioning, including dramatic play, memory and attention tasks, and self-regulatory private speech which involves telling oneself out loud what the appropriate behavior is. A recent evaluation indicated that children who are placed in the Tools of the Mind program demonstrated improved functioning compared to peers who were not in the program. Indeed, program involvement accounted for more variance in neuropsychological skills than age or gender (Diamond, Barnett, Thomas, \& Munro, 2007).

The general logic of targeting neuropsychological deficits relating to self-control is also at the core of the Promoting Alternative THinking Strategies (PATHS) Curriculum. Designed for school entry through fifth grade, PATHS is a comprehensive educational program taught three times per week for a minimum of 20 minutes per day. Among its targets are instruction on delaying gratification, controlling impulses, self-talk, self-awareness, reading and interpreting social cues and the needs/perspective of others, verbal skills, nonverbal communication, problem solving, and decision making. Improvements in these target areas contribute to an assortment of positive program outcomes, including improved self-control, reduced conduct problems, reduced anxiety/depression symptoms, and reduced aggression, and PATHS is hailed as a model prevention program (Greenberg, Kusche, \& Mihalic, 2006). Moreover, the program costs are just \$45 per student per year.

Despite their moderate to strong heritability ${ }^{2}$, neuropsychological deficits relating to self-control can be targeted even among older adults. For instance, focused attention

\footnotetext{
${ }^{2}$ The behavioral genetics of neuropsychological deficits are beyond the scope of the current article. However, it is important to note that neurological deficits demonstrate high heritability, and the genetic covariation between cognitive deficits and allied
} 
International Journal of Child, Youth and Family Studies (2011) 1 \& 2: 12-35.

meditation training is theorized to enhance the ability of individuals to focus their attention for greater intervals without relying on executive skills to purposely regulate attention during lapses. Since self-regulation problems centering on impulsivity are importantly related to school performance and conduct problems, increases in attention skills can serve to enhance school performance. Recently, Lutz et al. (2009) evaluated the effects of a 3-month intensive training in focused attention meditation among adult respondents. They found that the program increased the stability of attention, reduced the effort required to sustain attention, and sharpened brain responses (as measured by electroencephalography) to task-related sensory inputs. The most promising implication is that if the program is effective among adults (average age was 41), it would likely be more effective among children whose neural development is in a state of greater plasticity. Indeed, children with greater attention skills are better able to regulate themselves emotionally and behaviorally (Calkins \& Keane, 2004).

\section{Temperament}

From a panoramic purview, temperament encompasses the ways that an individual self-regulates and responds or reacts to the environment. Temperament is defined differently by researchers (for reviews, see Clark, 2005; Tackett, Balsis, Oltmanns, \& Krueger, 2009; Wachs \& King, 1994; Wachs \& Kohnstamm, 2001) but is consistently theorized to include activity level, global mood, approach or appetitive behaviors, and withdrawal behaviors. Seminal personality researcher Allport (1961) defined temperament as, “the characteristic phenomena of an individual's nature, including his susceptibility to emotional stimulation, his customary strength and speed of response, the quality of his prevailing mood, and all the peculiarities of fluctuation and intensity of mood, these being phenomena regarded as dependent on constitutional makeup, and therefore largely hereditary in origin” (p. 34). A host of temperament models exist including Rothbart and colleagues' psychobiological model (Rothbart, Derryberry, \& Posner, 1994), Depue and Collins' (1999) neurobiological model, Cloninger's (1987; Cloninger, Svrakic, \& Przybeck, 1993) tripartite model, Strelau's (1994) arousal model, and Gray's (1982) behavioral inhibition system (BIS), behavioral activation system (BAS), and flight-fight system (FFS). Although there are important differences, there are

constructs are also moderate to high (Haworth \& Plomin, 2010). For instance, Plomin, Colledge, and Dale (2002) found that $50 \%$ of the variance between language disability among children is shared with general cognitive disability. And heritability estimates of $h^{2}=.92$ have been found for language and performance delay (or broader neuropsychological deficits) among preschool children (Eley, Dale, Bishop, Price, \& Plomin, 2001). The heritability of hyperactivity is also high at about $h^{2}=.80$ (Price, Simonoff, Waldman, Asherson, \& Plomin, 2001). The heritability of specific dimensions of temperament is also differentially heritable. For instance, Goldsmith, Lemery, Buss, and Campos (1999) found that soothability was 0\% heritable and based entirely on shared and nonshared environment. However, other dimensions including negative affect $\left(h^{2}=\right.$ $.64)$, distress to novelty $\left(h^{2}=.58\right)$, activity level $\left(h^{2}=.55\right)$, distress to limitations $\left(h^{2}=\right.$ $.66)$, and duration of orienting $\left(h^{2}=.45\right)$ were moderately heritable. 
International Journal of Child, Youth and Family Studies (2011) 1 \& 2: 12-35.

also important commonalities across models that center on three temperamental constructs. The first relates to activity level that is characterized by high-intensity approach behaviors. Variously known as extraversion or surgency, activity level manifests in impulsive, sensation-seeking behaviors. The second broad dimension of temperament centers on negative emotionality, which is characterized by feelings of anger, fear, sadness, discomfort, and anxiety. Individuals with high levels of negative emotionality are more aversive or annoying, traits that are conducive for negative social interactions. The third global dimension is known as self-control, effortful control, or inhibitory control and it relates to the ability of an individual to regulate and modulate behavior in the face of impulses.

The pioneers of the contemporary study of temperament are Alexander Thomas and Stella Chess (1977). Their New York Longitudinal Study examined 141 infants over a period of six years and utilized a reciprocal understanding of temperament where infant reaction patterns - assumed to be innate or biologically-driven - interacted with environmental conditions, such as the responses from their parents. Based on their observations, Thomas and Chess indentified nine dimensions of infant temperament that were believed to have strong implications for their psychological and social development. Their nine dimensions were: (a) activity level; (b) regularity in terms of eating, sleeping, and elimination; (c) adaptability characterized by responses to changes in their environment; (d) responses to novelty (e.g., approach or withdrawal); (e) responsiveness threshold; (f) intensity of reaction to others; (g) mood quality; (h) distractability; and (i) task persistence.

In addition, Thomas and Chess (1977; Thomas, Chess, Birch, Hertzig, \& Korn, 1963) suggested three general types of children with relatively coherent temperamental profiles. Easy children were well-adjusted and unlikely to display or develop conduct problems, difficult children were prone to conduct problems and externalizing conditions, and slow-to-warm children were more cautious, inhibited but still generally wellfunctioning and prosocial. Decades later, the same three profiles can be observed albeit using sophisticated latent profile analyses that locate unobserved groupings in data. Researchers in the Netherlands found a well-adjusted "typical" group, an "expressive" group with increased externalizing problems, and a "fearful” group at risk for internalizing problems (van den Akker, Dekovic, Prinzie, \& Asscher, 2010). Another critical contribution of Thomas and Chess was the concept of "goodness of fit" where caregivers were cognizant of temperamental biases of children and could modify parenting behaviors to facilitate good outcomes and minimize opportunities for maladjustment.

It is during the first year of life that the temperamental seeds of both positive and negative behaviors are seen. It is also during the first year of life that parents respond to the temperamental cues from their infants, and adjust their parenting behaviors accordingly. Infants who are agreeable and unfussy, and predictable in their behaviors suggesting self-regulation - are at very low risk for problem behaviors later in life. Such children are also relatively easy to parent because caregiving is a relatively facile experience. On the other hand, infants who are fussy, irritable, and more difficult to 
International Journal of Child, Youth and Family Studies (2011) 1 \& 2: 12-35.

predict in terms of their day-to-day behavior are more challenging. Far from a facile experience, parenting a child with a more difficult temperament leads to aversive parentchild interactions (Patterson, 1982) and sets into motion the coercive family dynamics that are linked to problem behaviors occurring through adolescence (Lahey et al., 2008). ${ }^{3}$

The temperament literature is voluminous, and there are many examples of the continuity and stability of temperamental profiles. To illustrate, Caspi, Silva, and their colleagues (1996) tracked a birth cohort from Dunedin, New Zealand and explored their personality and temperamental paths from ages 3 to 21 . They found three types that were consistent with those developed by Thomas and Chess (1977). The well-adjusted type included children who were capable of self-control, were adequately self-confident, and were generally fine when faced with new situations or upon meeting new people. The inhibited type included children who were fearful, socially reticent, and easily upset by strangers. The undercontrolled type $-10 \%$ of the sample - included children who were impulsive, restless, negativistic or disagreeable, and emotionally labile. These were their characteristics at age 3 . Between ages 5 and 11, the undercontrolled children were consistently and significantly rated by parents and teachers to have externalizing problems. By ages 13 to 15, the undercontrolled at age 3 group continued to be noteworthy for their externalizing behaviors in addition to internalizing problems. By 18, undercontrolled children had low constraint, were admittedly reckless and careless, enjoyed dangerous and exciting activities, scored high on negative emotionality, were aggressive, and felt alienated and mistreated by others. At 21, formerly undercontrolled children reported employment difficulties and conflicts with family and romantic partners. They were described as conflict-prone, unreliable, and untrustworthy. They had problems with alcohol and often had extensive criminal records. Similar continuity was observed for the other two groups. Inhibited children developed into lives characterized as depressive, lacking agency and social connection, and prone to internalizing problems. They comprised 8\% of the Dunedin sample. The well-adjusted type developed into normal young adults (Caspi, 2000; Caspi et al., 2003; Caspi, \& Silva, 1995).

Temperamentally-based behavioral observations made at age 3 also significantly predict adult outcomes. For instance, Caspi, Moffitt, Newman, and Silva (1996) conducted a longitudinal-epidemiological study where 3-year-old children were classified into groups based on their behavioral disposition and reassessed at age 21 . Those who were described as undercontrolled or impulsive at age 3 were 2.9 times more likely than non-impulsive children to be diagnosed with antisocial personality disorder at age 21 .

${ }^{3}$ It is important to note that these effects are meaningful across generations. For instance, drawing on data from three generations of the Oregon Youth Study, Kerr, Capaldi, Pears, and Owen (2009) found linkages between a difficult temperament and conduct problems over three generations. In generation one, there was an association between parenting styles, the child's difficult temperament (e.g., high activity level, high impulsivity, high anger, and low inhibitory control), and antisocial conduct during both childhood and adolescence. By the third generation, there remained significant linkages between the respondent's temperament and his or her involvement in externalizing behaviors. 
International Journal of Child, Youth and Family Studies (2011) 1 \& 2: 12-35.

Moreover, they were 2.2 times as likely to be repeat offenders and 4.5 times more likely to be convicted of a violent crime. Compared to a control group, formerly impulsive children were also more likely to attempt suicide and have alcohol problems. In this sense, serious adult psychopathology was the outcome of readily observable impulsivity problems at age 3. These effects were also seen at age 26 (Caspi et al., 2003).

In a classic study, Caspi, Elder, and Bem (1987) examined longitudinal data spanning 30 years on boys and girls ages 8 to 10 who had frequent temper tantrums. Were temper tantrums merely a passing phase of late childhood or did they have enduring meaning? The results were alarming. They found that the explosive, poorly tempered outbursts of childhood also emerged later in adulthood under contexts when people had to subordinate themselves such as work and school settings. Having a bad temper as a child predicted middle adulthood occupational mobility (i.e., frequent job changes due to quitting or firing), educational attainment, and divorce and these effects were similar for males and females. ${ }^{4}$ Additional investigators using different data have similarly found difficult temperamental profiles observed in the first years of life can have enduring and negative consequences through kindergarten (Berdan, Keane, \& Calkins, 2008), elementary school (Rende \& Plomin, 1992; Slomkowski, Nelson, Dunn, \& Plomin, 1992), middle school (Séguin, Pihl, Harden, Tremblay, \& Bulerice, 1995), and adulthood (Kagan, 1994, 2010).

The temperament concept of effortful control is important because it conceptually relates to a construct that has greater currency in criminological research: self-control (Gottfredson \& Hirschi, 1990). Drawing on data from the National Institute of Child Health and Human Development Early Child Care Research Network Study of Early Child Care, Vazsonyi and Huang (2010) recently examined the stability of selfcontrol over a 10-year period when the children were ages 4.5 to 10.5 . Over a period that began during the preschool years and extended toward the end of elementary school, they found considerable stability in self-control. Preschoolers who were characterized by very low levels of self-control (measured as one standard deviation below the mean) remained that way throughout the study period. More importantly, by age 10.5, they were most discrepant from their peers. Similarly, children who were average and those who were above average (measured as one standard deviation above the mean) were stable across the six years. Self-control also was strongly associated with deviance.

\footnotetext{
${ }^{4}$ Temperament is also a useful variable for understanding the sheer differences between males and females in conduct problems. For instance, the prevalence of life-coursepersistent conduct problems is dramatically higher among males than females, with a sex ratio ranging from 10:1 to 15:1 across studies (see Eme, 2010). The constellation of traits of youth who develop lifelong conduct problems are captured by gender differences in temperament and these gender differences clearly disadvantage males. For example, meta-analytic research found that males have significantly lower levels of effortful control than females and males have significantly higher levels of surgency/activity than females (Else-Quest, Hyde, Goldsmith, \& Van Hulle, 2006). Both of these temperamental biases are associated with externalizing behaviors.
} 
International Journal of Child, Youth and Family Studies (2011) 1 \& 2: 12-35.

Given the two-pronged importance of temperament to problem behaviors, independently and interactively with parenting, it is a critical target for prevention (also see, Blair \& Diamond, 2008). In this sense, a focus on prevention takes the standard procedures from traditional prevention programs and tailors them to the "goodness of fit" between the temperamental disposition of the child and their rearing environment. Although temperament is a moderately heritable construct, it is amenable to program change as evidenced by prior research. For example, the Temperament Intervention for Parents Study (TIPS) at Arizona State University College of Nursing was designed to help parents modify the problem behavior of their children by understanding their temperament. TIPS involved randomized groups of parents who received no information (controls), an information group that received instruction on parent management strategies, and a nurse intervention group that received personal intervention on their child's temperament from a pediatric nurse. Although the program was not formally evaluated, a focus on the child's temperamental responses and strategies to reduce problems can enhance parenting, improve parent-child relations, and reduce the occurrence of problem behaviors (Melvin, 1995).

In a randomized, controlled study, Landry, Smith, and Swank (2006) found that mothers who received videotaped problem-solving training during 10 home visits increased their responsiveness to their infants between ages 6 and 13 months. The increases in maternal responsiveness enhanced the competence of the children to lay a foundation for prosocial behavior. Moreover, the responsiveness training theoretically helped to guard against the coercive processes that can engender conduct problems. Indeed, van den Boom (1995) found that a parent-skills training provided to mothers of irritable infants in the first year of their children's life had enduring effects on parent responsiveness, parent attachment, and child cooperation. Similarly, the Family Foundations program is a universal prevention program that consists of eight interactive psychoeducational skills-based classes for expectant couples. In addition to parenting, parent and child well-being, and parent-child relations, Family Foundations also targets temperamental concepts relating to infant orienting ability, infant soothability, and infant sleep. Evaluation of a randomized study found that infants in families that received the intervention demonstrated greater duration of orienting, greater soothability and closeness with fathers, reduced anxiety and depressive symptoms with mothers, and overall greater coparental support. The largest effect size was for reductions in father-reported dysfunctional interaction with the child (Feinberg \& Kan, 2008).

More dramatic effects have been shown for interventions that target temperamental inhibition. Kennedy, Rapee, and Edwards (2009) conducted a study of 71 children ages 3 to 4 who met diagnostic criteria for an anxiety disorder and who had a parent with a current anxiety disorder. The children were randomly assigned to an eightsession intervention that provided training on the understanding and treatment of excessive anxiety in children and ways to cope with it or to a wait-list control condition. Children in the intervention showed significant alterations to their inhibited temperament including increased speech or talkativeness, increased interaction with an adult stranger, and increased distance from their mother during social interaction. Although it is an overly uninhibited temperament that is associated with externalizing conditions, an 
International Journal of Child, Youth and Family Studies (2011) 1 \& 2: 12-35.

extremely inhibited temperament with its attendant anxiety and depressive symptoms is strongly associated with internalizing disorders (Kagan, 1994, 2010).

A policy focus on temperament can also yield reductions in problem behaviors occurring among adolescents. For example, evaluations of a large-scale longitudinal study - Tracking Adolescents’ Individual Lives Survey (TRAILS) - of Dutch adolescents have shown that good parenting practices and higher socioeconomic status can moderate temperamental risks such as frustration (or general negative emotionality) and fearfulness. Teens at risk for delinquency and other externalizing behaviors remained crime free when buffered by parents who provided emotional warmth and higher socioeconomic status (Sentse, Veenstra, Lindenberg, Verhulst, \& Ormel, 2009). These parent and socioeconomic effects are important because left unchecked, temperamental profiles clearly distinguish adolescents with externalizing problems. Specifically, youths with high levels of negative affect and low levels of effortful control are significantly at risk for problem behaviors.

In the end, prevention programs can also seek to produce outcomes that are consistent with temperamental profiles linked to well-adjusted, high functioning persons. A well-adjusted temperament is an established protective factor that offers resilience in criminogenic environments that contribute to problem behaviors among youths (Arthur, Hawkins, Pollard, Catalano, \& Baglioni, 2002). Indeed, in a study of the relationships between temperament and social competence among preschoolers in Head Start, Corapci (2008) found that children with temperaments characterized by low impulsivity and low inhibition demonstrated high levels of interactive peer play, which is suggestive of general sociality. In addition, teachers rated children with low impulsivity/low inhibition as more socially competent, and these are youths most likely to develop into functioning, prosocial adults.

\section{Discussion}

Prevention is a rare commodity in the world of public policy in that it enjoys proponents from all points of the political spectrum. It is humanistic to invest in social programs to improve the life chances of young people and their children, especially when those interventions are cost-effective compared to the costs of supervising and controlling offenders over their offending career. There is much to be excited about regarding the prevention literature, and if there is a common point to take away from prevention studies, it is that modest investments that target parenting practices not only improve the behavioral outcomes of young parents, particularly mothers, but also the behavioral outcomes of their children.

But a less sanguine conclusion is drawn from interventions that address the neurobiological traits of more severely behaviorally disturbed at-risk youths. This concern has been raised previously (e.g., Tremblay, 2006, 2010; Tremblay \& Szyf, 2010) and we suggest there is similar concern about neuropsychological deficits relating to selfcontrol and temperament. The immediate and long-term consequences of these constructs on serious antisocial behavior are alarming. For instance, Keenan and Wakschlag (2000) 
International Journal of Child, Youth and Family Studies (2011) 1 \& 2: 12-35.

reported that preschoolers as young as 30 months present symptoms that are consistent with serious behavioral disorders, such as ADHD, ODD, and CD. In their study of 79 clinic-referred preschool children ages 2.5 to 5.5 years, nearly $50 \%$ met criteria for conduct disorder and 75\% met criteria for ODD. Nearly 27\% met diagnostic criteria for all three disorders. Some of these children were so aggressive and uncontrollable that they were expelled from preschool.

Similarly, Campbell and Ewing (1990) found that 67\% of children who were rated as hard-to-manage at age 3 met diagnostic criteria for externalizing disorders at age 9 and the diagnostic data were validated by maternal and teacher reports. Hard-to-manage preschoolers display a troubling set of characteristics that lend themselves to prolonged antisocial conduct and compromised prosocial development. Mothers, fathers, and teachers report that hard-to-manage children as young as age 3 are noteworthy for their poor impulse control, oppositional tendencies, poorly developed social skills, inattention, and school problems (Campbell, 1994). These characteristics are not likely to dissipate merely because of increased family resources, improved parenting, and improved parentchild relations.

Although it is easy to suggest that more intensive intervention begun early may help these children with difficult-to-manage temperaments, there is little empirical evidence that this is the case. A more efficient approach for building prevention programs is to use principles derived from a biosocial understanding of the family dynamics and person-specific characteristics of those at risk of becoming habitual offenders is needed (see Caspi et al., 2002). This paradigm for increasing intervention efficacy and reducing serious violence is beginning to gain traction. For instance, from an epigenetics perspective, where processes such as DNA methylation and histone acetylation turn off or turn on genetic transcription, well-known prenatal risk factors including alcohol, drug, and tobacco use, poor nutrition, and maternal stress can be understood as "markers of environmental effects during development, including assessment of preventive and corrective intervention effects" (Tremblay, 2010, p. 356). In other words, these problems can be targeted not only for their role in the development of antisocial behavior from a traditional prevention and temperament perspective, but also for their contemporary role in biosocial understanding of the ways that genes, environments, and epigenetic environments play out.

We have not reinvented the wheel here. A clear focus on neuropsychological deficits and temperament sheds insight on the unifying ways that individuals consistently behave and consistently respond to their environments. This is well established in the temperament and developmental psychopathology literatures, and also appears on the radar screen in the prevention literature. But the primacy of biosocial constructs is relatively new to criminology and criminal justice. And although many of the constructs that were discussed in this article are under moderate to strong genetic influence, variance in these constructs is also importantly explained by environmental factors. Future research and intervention on modifying environmental factors in the hopes of producing beneficial outcomes would fruitfully benefit from including temperament and neuropsychological factors. Doing so would result in greater specification of the most 
International Journal of Child, Youth and Family Studies (2011) 1 \& 2: 12-35.

important environmental factors that could influence dispositional traits such as a difficult temperament. Moreover, in relation to what once seemed like fixed, constitutional factors that were impervious to change, the current review discussed several promising programs that directly address the neuropsychological deficits and difficult temperaments that give rise to problems over time. 
International Journal of Child, Youth and Family Studies (2011) 1 \& 2: 12-35.

\section{References}

Allport, G. W. (1961). Pattern and growth in personality. New York: Henry Holt.

Arthur, M. W., Hawkins, J. D., Pollard, J. A., Catalano, R. F., \& Baglioni, Jr., A. J. (2002). Measuring risk and protective factors for substance use, delinquency, and other adolescent problem behaviors: The Communities that Care Youth Survey. Evaluation Review, 26(6), 575-601.

Barker, E. D., Séguin, J. R., White, H. R., Bates, M. E., Lacourse, É, Carbonneau, R., et al. (2007). Developmental trajectories of male physical violence and theft: Relation to neurocognitive performance. Archives of General Psychiatry, 64(5), 592-599.

Barkley, R. A. (1997). Behavioral inhibition, sustained attention, and executive functions: Constructing a unifying theory of ADHD. Psychological Bulletin, 121(1), 65-94.

Beaver, K. M., DeLisi, M., Vaughn, M. G., \& Wright, J. P. (2010). The intersection of genes and neuropsychological deficits in the prediction of adolescent delinquency and low self-control. International Journal of Offender Therapy and Comparative Criminology, 54(1), 22-42.

Beaver, K. M., DeLisi, M., Wright, J. P., Vaughn, M. G., \& Boutwell, B. (2008). The mutual unfolding of self-control and language skills: Evidence of a common etiological pathway. Criminology, 46(4), 939-970.

Beaver, K. M., Wright, J. P., \& DeLisi, M. (2007). Self-control as an executive function: Reformulating Gottfredson and Hirschi's parental socialization thesis. Criminal Justice and Behavior, 34(10), 1345-1361.

Berdan, L. E., Keane, S. P., \& Calkins, S. D. (2008). Temperament and externalizing behavior: Social preference and perceived acceptance as protective factors. Developmental Psychology, 44(4), 957-968.

Blair, C., \& Diamond, A. (2008). Biological processes in prevention and intervention: The promoting of self-regulation as a means of preventing school failure. Development and Psychopathology, 20(3), 899-911.

Braga, A. A. (2008). Pulling levers: Focused deterrence strategies and the prevention of gun homicide. Journal of Criminal Justice, 36(4), 332-343. 
International Journal of Child, Youth and Family Studies (2011) 1 \& 2: 12-35.

Calkins, S. D., \& Keane, S. P. (2004). Cardiac vagal regulation across the preschool period: Stability, continuity, and implications for childhood adjustment. Developmental Psychobiology, 45(3), 101-112.

Campbell, S. B. (1994). Hard-to-manage preschool boys: Externalizing behavior, social competence, and family context at two-year follow-up. Journal of Abnormal Child Psychology, 22(2), 147-166.

Campbell, S. B., \& Ewing, L. J. (1990). Follow-up of hard-to-manage preschoolers: Adjustment at age 9 and predictors of continuing symptoms. Journal of Child Psychology and Psychiatry, 31(6), 871-889.

Caspi, A. (2000). The child is father of the man: Personality continuities from childhood to adulthood. Journal of Personality and Social Psychology, 78(1), 158-172.

Caspi, A., Elder, G. H., \& Bem, D. J. (1987). Moving against the world: Life-course patterns of explosive children. Developmental Psychology, 23(2), 308-313.

Caspi, A., Harrington, H., Milne, B., Amell, J. W., Theodore, R. F., \& Moffitt, T. E. (2003). Children's behavioral styles at age 3 are linked to their adult personality traits at age 26. Journal of Personality, 71(4), 495-514.

Caspi, A., McClay, J., Moffitt, T. E., Taylor, A., Craig, I. W., et al. (2002). Role of genotype in the cycle of violence in maltreated children. Science, 297(5582), 851-854.

Caspi, A., Moffitt, T. E., Newman, D. L., \& Silva, P. A. (1996). Behavioral observations at age 3 years predict adult psychiatric disorders: Longitudinal evidence from a birth cohort. Archives of General Psychiatry, 53(11), 1033-1039.

Caspi, A., \& Silva, P. A. (1995). Temperamental qualities at age 3 predict personality traits in young adulthood: Longitudinal evidence from a birth cohort. Child Development, 66(2), 486-498.

Clark, C., Prior, M., \& Kinsella, G. J. (2000). Do executive function deficits differentiate between adolescents with ADHD and Oppositional Defiant/Conduct Disorder? A neuropsychological study using the Six Elements Test and Hayling Sentence Completion Test. Journal of Abnormal Child Psychology, 28(5), 403-414.

Clark, L. A. (2005). Temperament as a unifying basis for personality and psychopathology. Journal of Abnormal Psychology, 114(4), 505-521.

Cloninger, C. R. (1987). A systematic method for clinical description and classification of personality variants: A proposal. Archives of General Psychiatry, 44(6), 573-588. 
International Journal of Child, Youth and Family Studies (2011) 1 \& 2: 12-35.

Cloninger, C. R., Svrakic, D. M., \& Przybeck, T. R. (1993). A psychobiological model of temperament and character. Archives of General Psychiatry, 50(12), 975-990.

Cohen, M. A. (1998). The monetary value of saving a high-risk youth. Journal of Quantitative Criminology, 14(1), 5-33.

Cohen, M. A. (2005). The costs of crime and justice. New York: Routledge.

Cohen, M. A., \& Piquero, A. R. (2009). New evidence on the monetary value of saving a high-risk youth. Journal of Quantitative Criminology, 25(1), 25-49.

Corapci, F. (2008). The role of child temperament on Head Start preschoolers' social competence in the context of cumulative risk. Journal of Applied Developmental Psychology, 29(1), 1-16.

DeLisi, M. (2005). Career criminals in society. Thousand Oaks, CA: Sage.

DeLisi, M., \& Gatling, J. M. (2003). Who pays for a life of crime? An empirical assessment of the assorted victimization costs posed by career criminals. Criminal Justice Studies, 16(4), 283-293.

DeLisi, M., Kosloski, A., Sween, M., Hachmeister, E., Moore, M., \& Drury, A. (2010). Murder by numbers: Monetary costs imposed by a sample of homicide offenders. The Journal of Forensic Psychiatry \& Psychology, 21(4), 501-513.

Depue, R., \& Collins, P. E. (1999). Neurobiology of the structure of personality: Dopamine, facilitation of incentive motivation, and extraversion. Behavioral and Brain Sciences, 22(3), 491-569.

Diamond, A., Barnett, W. S., Thomas, J., \& Munro, S. (2007). Preschool program improves cognitive control. Science, 318(5855), 1387-1388.

Dodge, K. A., \& McCourt, S. N. (2010). Translating models of antisocial behavioral development into efficacious intervention policy to prevent adolescent violence. Developmental Psychobiology, 52(3), 277-285.

Earls, F. (1998). Positive effects of prenatal and early childhood interventions. Journal of the American Medical Association, 280(14), 1271-1273.

Eley, T. C., Dale, P., Bishop, D., Price, T. S., \& Plomin, R. (2001). Longitudinal analysis of the genetic and environmental influences on components of cognitive delay in preschoolers. Journal of Educational Psychology, 93, 698-707.

Elliott, D. S. (1998a). Prevention programs that work for youth: Violence prevention. Boulder, CO: Center for the Study and Prevention of Violence. 
International Journal of Child, Youth and Family Studies (2011) 1 \& 2: 12-35.

Elliott, D. S. (1998b). Implementing and evaluating crime prevention and control programs and policies. Crime, Law \& Social Change, 28(3-4), 287-310.

Else-Quest, N. M., Hyde, J. S., Goldsmith, H. H., \& Van Hulle, C. A. (2006). Gender differences in temperament: A meta-analysis. Psychological Bulletin, 132(1), 33-72.

Eme, R. F. (2007). Sex differences in child-onset, life-course-persistent conduct disorder: A review of biological influences. Clinical Psychology Review, 27(5), 607-627.

Eme, R. F. (2010). Male life-course-persistent antisocial behavior. Archives of Pediatrics and Adolescent Medicine, 164(5), 486-487.

Farrington, D. P., \& Coid, J. W. (Eds.). (2003). Early prevention of adult antisocial behavior. New York: Cambridge University Press.

Farrington, D. P., \& Welsh, B. C. (2007). Saving children from a life of crime: Early risk factors and effective interventions. New York: Oxford University Press.

Feinberg, M. E., \& Kan, M. L. (2008). Establishing Family Foundations: Intervention effects on coparenting, parent/infant well-being, and parent-child relations. Journal of Family Psychology, 22(2), 253-263.

Foley, A. (2008). The current state of gender-specific delinquency programming. Journal of Criminal Justice, 36(3), 262-269.

Goldsmith, H. H., Lemery, K. S., Buss, K. A., \& Campos, J. J. (1999). Genetic analyses of focal aspects of infant temperament. Developmental Psychology, 35(4), 972-985.

Gottfredson, M. R., \& Hirschi, T. (1990). A general theory of crime. Stanford, CA: Stanford University Press.

Gray, J. A. (1982). Précis of: The neuropsychology of anxiety: An inquiry into the functions of the septo-hippocampal system. Behavioral and Brain Sciences, 5(3), 469-484.

Greenberg, M. T., Kusche, C., \& Mihalic, S. F. (2006). Promoting alternative thinking strategies (PATHS): Blueprints for violence prevention, Book Ten. Boulder, CO: Center for the Study and Prevention of Violence.

Haworth, C. M. A., \& Plomin, R. (2010). Quantitative genetics in the era of molecular genetics: Learning abilities and disabilities as an example. Journal of the American Academy of Child \& Adolescent Psychiatry, 49(8), 783-793. 
International Journal of Child, Youth and Family Studies (2011) 1 \& 2: 12-35.

Hinshaw, S. P. (1987). On the distinction between attentional deficits/hyperactivity and conduct problems/aggression in child psychopathology. Psychological Bulletin, 101, 443-463.

Hinshaw, S. P. (1992). Externalizing behavior problems and academic underachievement in childhood and adolescence: Causal relationships and underlying mechanisms. Psychological Bulletin, 111, 127-155.

Hinshaw, S. P., Carte, E. T., Sami, N., Treuting, J. J., \& Zupan, B. A. (2002). Preadolescent girls with ADHD: II. Neuropsychological performance in relation to subtypes and individual classification. Journal of Consulting and Clinical Psychology, 70(5), 1099-1111.

Ishikawa, S. S., \& Raine, A. (2003). Prefrontal deficits and antisocial behavior: A causal model. In B. B. Lahey, T. E. Moffitt, \& A. Caspi (Eds.), Causes of conduct disorder and juvenile delinquency (pp. 277-304). New York: The Guilford Press.

Kagan, J. (1994). Galen’s prophecy: Temperament in human nature. New York: Basic Books.

Kagan, J. (2010). The temperamental thread: How genes, culture, time, and luck make us who we are. New York: Dana Press.

Keenan, K., \& Wakschlag, L. S. (2000). More than the terrible twos: The nature and severity of behavior problems in clinic-referred preschool children. Journal of Abnormal Child Psychology, 28(1), 33-46.

Kennedy, S. J., Rapee, R. M., \& Edwards, S. L. (2009). A selective intervention program for inhibited preschool-aged children of parents with an anxiety disorder: Effects on current anxiety disorders and temperament. Journal of American Academy of Child and Adolescent Psychiatry, 48(6), 602-609.

Kerr, D. C. R., Capaldi, D. M., Pears, K. C., \& Owen, L. D. (2009). A prospective three generational study of fathers' constructive parenting: Influences from family of origin, adolescent adjustment, and offspring temperament. Developmental Psychology, 45(5), 1257-1275.

Kitzman, H. J., Olds, D. L., Cole, R. E., Hanks, C. A., Anson, E. A., Arcoleo, K. J., et al. (2010). Enduring effects of prenatal and infancy home visiting by nurses on children: Follow-up of a randomized trial among children at age 12 years. Archives of Pediatrics \& Adolescent Medicine, 164(5), 412-418.

Lahey, B. B., Van Hulle, C. A., Keenan, K., Rathouz, P. J., D’Onofrio, B. M., Rodgers, J. L., et al. (2008). Temperament and parenting during the first year of life predict future child conduct problems. Journal of Abnormal Child Psychology, 36(8), 1139-1158. 
International Journal of Child, Youth and Family Studies (2011) 1 \& 2: 12-35.

Landry, S. H., Smith, K. E., \& Swank, P. R. (2006). Responsive parenting: Establishing early foundations for social, communication, and independent problem-solving skills. Developmental Psychology, 42(4), 627-642.

Litschge, C. M., Vaughn, M. G., \& McCrae, C. (2010). The empirical status of interventions for children and youth with conduct problems: An overview of meta-analytic studies. Research on Social Work Practice, 20(1), 21-35.

Lutz, A., Slagter, H. A., Rawlings, N. B., Francis, A. D., Greischar, L. L., \& Davidson, R. J. (2009). Mental training enhances attentional stability: Neural and behavioral evidence. The Journal of Neuroscience, 29(42), 13418-13427.

Mears, D. P. (2007). Towards rational and evidence-based crime policy. Journal of Criminal Justice, 35(6), 667-682.

Mears, D. P., \& Bacon, S. (2009). Improving criminal justice through better decision making: Lessons from the medical system. Journal of Criminal Justice, 37(2), 142-154.

Mears, D. P., \& Barnes, J. C. (2010). Toward a systematic foundation for identifying evidence-based criminal justice sanctions and their relative effectiveness. Journal of Criminal Justice, 38(4), 702-710.

Melvin, N. (1995). Children's temperament: Intervention for parents. Journal of Pediatric Nursing, 10(3), 152-159.

Moffitt, T. E. (1993). Adolescence-limited and life-course-persistent antisocial behavior: A developmental taxonomy. Psychological Review, 100, 674-701.

Moffitt, T. E. (2005). The new look of behavioral genetics in developmental psychopathology: Gene-environment interplay in antisocial behaviors. Psychological Bulletin, 131, 533-554.

Moffitt, T. E., Caspi, A., \& Rutter, M. (2006). Measured gene-environment interactions in psychopathology: Concepts, research strategies, and implications for research, intervention, and public understanding of genetics. Perspectives on Psychological Science, 1(1), 5-27.

Moffitt, T. E., \& Henry, B. (1989). Neuropsychological assessment of executive functions in self-reported delinquents. Development and Psychopathology, 1(2), 105-118. 
International Journal of Child, Youth and Family Studies (2011) 1 \& 2: 12-35.

Moffitt, T. E., \& Silva, P. A. (1988). Neuropsychological deficit and self-reported delinquency in an unselected birth cohort. Journal of the American Academy of Child \& Adolescent Psychiatry, 27(2), 233-240.

Nigg, J. T., Hinshaw, S. P., Carte, E. T., \& Treuting, J. J. (1998). Neuropsychological correlates of childhood ADHD: Explainable by comorbid disruptive behavior or reading problems? Journal of Abnormal Psychology, 107(3), 468-480.

Olds, D. L. (2002). Prenatal and infancy home visiting by nurses: From randomized trials to community replication. Prevention Science, 3(3), 153-172.

Olds, D. L., Eckenrode, J., Henderson, Jr., C. R., Kitzman, H., Powers, J., Cole, R., et al. (1997). Long-term effects of home visitation on maternal life course and child abuse and neglect. Journal of the American Medical Association, 278(8), 637-643.

Olds, D. L., Henderson, Jr., C. R., Cole, R., Eckenrode, J., Kitzman, H., Luckey, D., et al. (1998). Long-term effects of nurse home visitation on children's criminal and antisocial behavior: 15-year follow-up of a randomized controlled trial. Journal of the American Medical Association, 280(14), 1238-1244.

Olds, D. L., Henderson, Jr., C. R., \& Kitzman, H. (1994). Does prenatal and infancy nurse home visitation have enduring effects on qualities of parental caregiving and child health at 25 to 50 months of life? Pediatrics, 93(1), 89-98.

Olds, D. L., Kitzman, H., Cole, R., Robinson, J., Sidora, K., Luckey, D. W., et al. (2004). Effects of nurse home-visiting on maternal life course and child development: Age 6 follow-up results of a randomized trial. Pediatrics, 114(6), 1550-1559.

Patterson, G. R. (1982). Coercive family process. Eugene, OR: Castalia.

Plomin, R., Colledge, E., \& Dale, P. S. (2002). Genetics and the development of language disabilities and abilities. Current Paediatrics, 12(5), 419-424.

Price, T. S., Simonoff, E., Waldman, I., Asherson, P., \& Plomin, R. (2001). Hyperactivity in preschool children is highly heritable. Journal of the American Academy of Child \& Adolescent Psychiatry, 40(12), 1362-1364.

Raine, A., Moffitt, T. E., Caspi, A., Loeber, R., Stouthamer-Loeber, M., \& Lynam, D. (2005). Neurocognitive impairments in boys on the life-course persistent antisocial path. Journal of Abnormal Psychology, 114(1), 38-49.

Rende, R. D., \& Plomin, R. (1992). Relations between first grade stress, temperament, and behavior problems. Journal of Applied Developmental Psychology, 13(4), 435-446. 
International Journal of Child, Youth and Family Studies (2011) 1 \& 2: 12-35.

Rothbart, M. K., Derryberry, D., \& Posner, M. I. (1994). A psychobiological approach to the development of temperament. In J. E. Bates \& T. D. Wachs (Eds.), Temperament: Individual differences at the interface of biology and behavior (pp. 83-116). Washington, DC: American Psychological Association.

Schweinhart, L. J., Barnes, H. V., Weikart, D. P., Barnett, W. S., \& Epstein, A. S. (1993). Significant benefits: The High/Scope Perry Preschool Study through age 27. Ypsilanti, MI: High/Scope Press.

Séguin, J. R., Arsenault, L., \& Tremblay, R. E. (2007). The contribution of “cool” and "hot" components of decision-making in adolescence: Implications for developmental psychopathology. Cognitive Development, 22(4), 530-543.

Séguin, J. R., Nagin, D., Assaad, J.-M., \& Tremblay, R. E. (2004). Cognitiveneuropsychological function in chronic physical aggression and hyperactivity. Journal of Abnormal Psychology, 113(4), 603-613.

Séguin, J. R., Pihl, R. O., Harden, P. W., Tremblay, R. E., \& Boulerice, B. (1995). Cognitive and neuropsychological characteristics of physically aggressive boys. Journal of Abnormal Psychology, 104(4), 614-624.

Sentse, M., Veenstra, R., Lindenberg, S., Verhulst, F. C., \& Ormel, J. (2009). Buffers and risks in temperament and family for early adolescent psychopathology: Generic, conditional, or domain-specific effects? The TRAILS study. Developmental Psychology, 45(2), 419-430.

Shaw, D. S., \& Gross, H. E. (2008). What we have learned about early childhood and the development of delinquency. In A. M. Liberman (Ed.), The long view of crime: A synthesis of longitudinal research (pp. 79-127). New York: Springer.

Slomkowski, C. L., Nelson, K., Dunn, J., \& Plomin, R. (1992). Temperament and language: Relations from toddlerhood to middle childhood. Developmental Psychology, 28(6), 1090-1095.

Strelau, J. (1994). The concepts of arousal and arousability as used in temperament studies. In J. E. Bates \& T. D. Wachs (Eds.), Temperament: Individual differences at the interface of biology and behavior (pp. 117-141). Washington, DC: American Psychological Association.

Tackett, J. L., Balsis, S., Oltmanns, T. F., \& Krueger, R. F. (2009). A unifying perspective on personality pathology across the life span: Developmental considerations for the fifth edition of the Diagnostic and Statistical Manual of Mental Disorders. Development and Psychopathology, 21(3), 687-713. 
International Journal of Child, Youth and Family Studies (2011) 1 \& 2: 12-35.

Thomas, A., \& Chess, S. (1977). Temperament and development. New York: Brunner/Mazel.

Thomas, A., Chess, S., Birch, H. G., Hertzig, M. E., \& Korn, S. (1963). Behavioral individuality in early childhood. New York: New York University Press.

Tremblay, R. E. (2006). Prevention of youth violence: Why not start at the beginning? Journal of Abnormal Child Psychology, 34, 481-487.

Tremblay, R. E. (2010). Developmental origins of disruptive behavior problems: The 'original sin' hypothesis, epigenetics and their consequences for prevention. Journal of Child Psychology and Psychiatry, 51(4), 341-367.

Tremblay, R. E., \& Szyf, M. (2010). Developmental origins of chronic physical aggression and epigenetics. Epigenomics, 2(4), 495-499.

van den Akker, A. L., Dekovic, M., Prinzie, P., \& Asscher, J. J. (2010). Toddlers' temperament profiles: Stability and relations to negative and positive parenting. Journal of Abnormal Child Psychology, 38, 485-495.

van den Boom, D. C. (1995). Do first-year intervention effects endure? Follow-up during toddlerhood of a sample of Dutch irritable infants. Child Development, 66(6), 1798-1816.

Vaughn, M. G., DeLisi, M., Beaver, K. M., \& Wright, J. P. (2009). Identifying latent classes of behavioral risk based on early childhood manifestations of self-control. Youth Violence and Juvenile Justice, 7(1), 16-31.

Vazsonyi, A. T., \& Huang, L. (2010). Where self-control comes from: On the development of self-control and its relationship to deviance over time. Developmental Psychology, 46(1), 245-257.

Wachs, T. D., \& Kohnstamm, G. A. (Eds.). (2001). Temperament in context. Mahwah, NJ: Lawrence Erlbaum Associates, Publishers.

Wachs, T. D., \& King, B. (1994). Behavioral research in the brave new world of neuroscience and temperament: A guide to the biologically perplexed. In J. E. Bates \& T. D. Wachs (Eds.), Temperament: Individual differences at the interface of biology and behavior (pp. 307-336). Washington, DC: American Psychological Association.

Walton, M. A., Chermack, S. T., Shope, J. T., Bingham, C. R., Zimmerman, M. A., Blow, F. C., et al. (2010). Effects of a brief intervention for reducing violence and alcohol misuse among adolescents. Journal of the American Medical Association, 304(5), 527-535. 
International Journal of Child, Youth and Family Studies (2011) 1 \& 2: 12-35.

Weikart, D. P. (1998). Changing early childhood development through educational intervention. Preventive Medicine, 27(2), 233-237.

Welsh, B. C., Loeber, R., Stevens, B. R., Stouthamer-Loeber, M., Cohen, M. A., \& Farrington, D. P. (2008). The costs of juvenile crime in urban areas: A longitudinal perspective. Youth Violence and Juvenile Justice, 6(1), 3-27.

White, H. R., Bates, M. E., \& Buyske, S. (2001). Adolescence-limited versus persistent delinquency: Extending Moffitt's hypothesis into adulthood. Journal of Abnormal Psychology, 110(4), 600-609.

White, J. L., Moffitt, T. E., Caspi, A., Bartusch, D. J., Needles, D. J., \& StouthamerLoeber, M. (1994). Measuring impulsivity and examining its relationship to delinquency. Journal of Abnormal Psychology, 103(2), 192-205.

Worrall, J. L., Hiromoto, S., Merritt, N., Du, D., Jacobson, J. O., \& Iguchi, M. Y. (2009). Crime trends and the effect of mandated drug treatment: Evidence from California’s Substance Abuse and Crime Prevention Act. Journal of Criminal Justice, 37(2), 109-113. 